\title{
Properties of Self-Compacting Concrete with Recycled Coarse Aggregate
}

\author{
W. C. Tang, ${ }^{1}$ P. C. Ryan, ${ }^{2}$ H. Z. Cui, ${ }^{3}$ and W. Liao ${ }^{4}$ \\ ${ }^{1}$ School of Architecture and Built Environment, The University of Newcastle, Callaghan, NSW 2308, Australia \\ ${ }^{2}$ College of Engineering and Informatics, National University of Ireland, Galway, Ireland \\ ${ }^{3}$ Guangdong Provincial Key Laboratory of Durability for Marine Civil Engineering, Shenzhen University, China \\ ${ }^{4}$ Department of Architecture and Civil Engineering, City University of Hong Kong, Hong Kong
}

Correspondence should be addressed to W. C. Tang; patrick.tang@newcastle.edu.au

Received 7 December 2015; Revised 16 February 2016; Accepted 17 February 2016

Academic Editor: Osman Gencel

Copyright (c) 2016 W. C. Tang et al. This is an open access article distributed under the Creative Commons Attribution License, which permits unrestricted use, distribution, and reproduction in any medium, provided the original work is properly cited.

\begin{abstract}
The utilisation of recycled concrete aggregate (RCA) in Self-Compacting Concrete (SCC) has the potential to reduce both the environmental impact and financial cost associated with this increasingly popular concrete type. However, to date limited research exists exploring the use of coarse RCA in SCC. The work presented in this paper seeks to build on the existing knowledge in this area by examining the workability, strength, and fracture properties of SCCs containing $0 \%, 25 \%, 50 \%, 75 \%$, and $100 \%$ coarse RCA. The experimental programme indicated that at RCA utilisation levels of $25 \%$ to $50 \%$ little or no negative impact was observed for strength, workability, or fracture properties, with the exception of a slight reduction in Young's modulus.
\end{abstract}

\section{Introduction}

The importance of establishing the suitability of recycled aggregates has increased in recent years against the backdrop of a growing emphasis on sustainable building practices. As pointed out by Padmini et al. [1], the rate of building demolition is constantly increasing, making it essential to effectively reuse demolition waste to conserve nonrenewable natural resources. At present a large portion of potentially useful construction and demolition waste is disposed of in landfill sites, creating environmental problems due to scarcity of such sites, unplanned disposal, and environmental cost of transporting demolition waste [2]. The use of coarse recycled concrete aggregates (RCAs) as a replacement for natural coarse aggregates in concrete offers a sustainable solution to these problems. However, the use of RCA may potentially reduce concrete quality as coarse RCAs are generally of poorer quality than natural coarse aggregates, with greater water absorption [3,4] and lower density [5]. This reduced quality is due to the fact that coarse RCA consists of both original aggregate and adhered mortar; thus the quality of the RCA depends not only on the original aggregate, but also on the quality and quantity of adhered mortar. The use of RCA also affects the characteristics of the interfacial transition zones between aggregates and cement paste [6], which in turn affects the strength characteristics of concrete containing RCA. When considering the mechanical properties of concrete with RCA, most of the previous researches confirmed that the reduction in stiffness (i.e., elastic modulus) is higher than the reduction in strength [7-10].

Another important consideration is the possible reduction in workability of concretes incorporating coarse RCA, due to the increased angularity and surface roughness of RCA when compared to natural coarse aggregates $[1,4]$. This is of particular importance for the increasingly popular form of concrete known as Self-Compacting Concrete (SCC) [11]. The Eurocode [12] defines SCC as concrete that is able to flow and compact under its own weight, fill formwork with its reinforcement, duct box houses, and so forth, whilst maintaining homogeneity. It is a relatively recent form of concrete construction having been developed in Japan in the mid1980s and introduced in Europe in the mid-1990s. Despite its recent development, SCC is now widely used in industry due to the advantages of SCC which include increased on-site productivity, enhanced construction quality, and improved working conditions on-site [13, 14]. However, as pointed out 
by Tuyan et al. [3], the cost of SCC is higher than traditional vibrated concretes due to the need for higher powder contents and chemical admixtures in SCC. Thus in order to allow SCC to reach its full potential in terms of industry uptake it is necessary to develop ways of making SCC more costeffective. The use of coarse RCA as substitutes for coarse natural aggregates in SCC offers a means of reducing the cost of SCC, while reducing the carbon footprint of concrete production. Consequently, there are both business case and an environmental obligation to explore the use of RCA in SCCs.

This paper examines the use of varying proportions of coarse RCA in SCC. The work presented herein builds on the existing body of literature by examining the fresh concrete properties of SCCs containing RCA. This is an important area which has been examined by a number of researchers in recent years including $[3-5,15,16]$. The primary contribution of this paper, however, lies in the examination of the hardened properties of SCCs containing various levels of RCA and, most importantly, the examination of the fracture properties of SCC containing RCA. It is recognized that the fracture properties of concrete constitute fundamental characteristics in design and safety assessment of structures, especially large-scale structures $[17,18]$. As pointed out by Bordelon et al. [19], examination of compressive strength and tensile strength alone does not give a complete picture of structural performance due to the interaction of the material behaviour, preexisting cracks, and geometry of the structure. Bordelon et al. [19] thus stated that the concrete fracture properties can provide greater insight into the potential load carrying capacity of the material in a given structural system. These fracture properties are heavily dependent on the components in the mixture [17], with fracture energy depending largely on the quality of the ITZ and the properties of the coarse aggregate [20]. Thus utilisation of coarse RCA as a replacement for natural coarse aggregate may have a notable influence on concrete fracture energy. As stated by Butler et al. [20] however, there are very few studies which examine the fracture energy of vibrated concretes containing coarse RCA $[6,19,20]$. Even less knowledge exists for SCCs, with little or no research currently available exploring the fracture energy implications of RCA use in SCCs, which have different ITZ characteristics and mix compositions to normal vibrated concretes $[21,22]$. The work in this paper seeks to address this important gap in the existing literature by exploring the fracture energy of SCCs with natural coarse aggregate replaced with RCA at levels of $0 \%$ (control), 25\%, 50\%, 75\%, and $100 \%$. SCC strength characteristics are also examined at each of the RCA utilisation levels to enhance understanding of the effect of RCA on these properties.

\section{Materials and Methods}

2.1. Materials. The binder content for all the SCC mixes examined herein consisted of Ordinary Portland Cement (OPC), fly ash (FA), and silica fume (SF). The OPC used was ASTM Type I Portland cement, with a fineness of $3520 \mathrm{~cm}^{2} / \mathrm{g}$ and density of $3150 \mathrm{~kg} / \mathrm{m}^{3}$. The FA and SF were used in accordance with EN 450-1:2005A [23] and ASTM
TABLE 1: Properties of natural and recycled coarse aggregates.

\begin{tabular}{lccc}
\hline Type & $\begin{array}{c}\text { Nominal size } \\
(\mathrm{mm})\end{array}$ & $\begin{array}{c}\text { Density } \\
\left(\mathrm{kg} / \mathrm{m}^{3}\right)\end{array}$ & $\begin{array}{c}\text { Water } \\
\text { absorption } \\
\left(\mathrm{kg} / \mathrm{m}^{3}\right)\end{array}$ \\
\hline Crushed granite & 10 & 2650 & 1.15 \\
Recycled aggregate & 10 & 2450 & 7.75 \\
\hline
\end{tabular}

C 1240-11 [24], respectively. The recycled aggregate used was a crushed and unwashed recycled concrete aggregate, with a nominal size of $10 \mathrm{~mm}$ sourced from a construction and demolition waste recycling facility. The coarse natural aggregate consisted of crushed granite with a nominal size of $10 \mathrm{~mm}$. Table 1 presents the water absorption ( 24 hours) and density of the natural and recycled coarse aggregates. The fine aggregate used in the study was river sand, with a fineness modulus of 2.65. The particle size distributions of all the aggregates used were in accordance with the requirements of EN 12620:2002A [25].

As mentioned in the previous section, five different SCC mixes were examined herein, with percentages of substitution of natural coarse aggregates with RCA of $0 \%, 25 \%, 50 \%, 75 \%$, and $100 \%$. Mix design details (based on aggregates being in the saturated surface dry condition) for each of these five mixes are presented in Table 2 . The water/binder $(\mathrm{w} / \mathrm{b})$ ratio and superplasticizer dosage were the same for the five mixes examined. For the experimental programme described in this paper, the natural and recycled coarse aggregates were immersed in water for 24 hours and left for 1 hour in air before concrete mixing to reach surface dry condition.

\subsection{Test Methods and Sample Preparations}

2.2.1. Fresh Concrete Tests. The three tests used to investigate the fresh properties of the SCCs were the slump flow test, the L-box test, and the sieve segregation test, as shown in Figure 1. These three tests assess the primary characteristics of fresh SCC. The slump flow test and $t_{500}$ time evaluate the flowability and viscosity of a SCC in the absence of any obstruction, respectively [26]. The slump flow diameter (Figure 1(a)) is the measurement required for all SCC in accordance with EN 206-9:2010 [12]. The Eurocode states that SCC should have a slump flow value of between $550 \mathrm{~mm}$ and $850 \mathrm{~mm}$, while $t_{500}$ times less than two seconds result in VS1 classification, while $t_{500}$ times greater than or equal to two seconds result in a VS2 classification.

The L-box test, as shown in Figure 1(b), was performed in accordance with EN 12350-12350-10 [27]. This test is used to assess the passing ability of SCC. EN 206-9:2010 (2010) states that for an L-box with three reinforcement bars the blocking ratio ( $B$ value) should be greater than or equal to 0.80 [12]. The final workability test, the sieve segregation test (shown in Figure 1(c)), was performed in accordance with EN 12350-11:2010 [28]. The test examines resistance of SCC to segregation by measuring the mass of fresh concrete which passes through a $5 \mathrm{~mm}$ sieve, when poured from a height of $50 \mathrm{~cm} \pm 5 \mathrm{~cm}$. EN 206-9:2010 states that the percentage passing the sieve $(P)$ should be less than $20 \%$ [12]. 


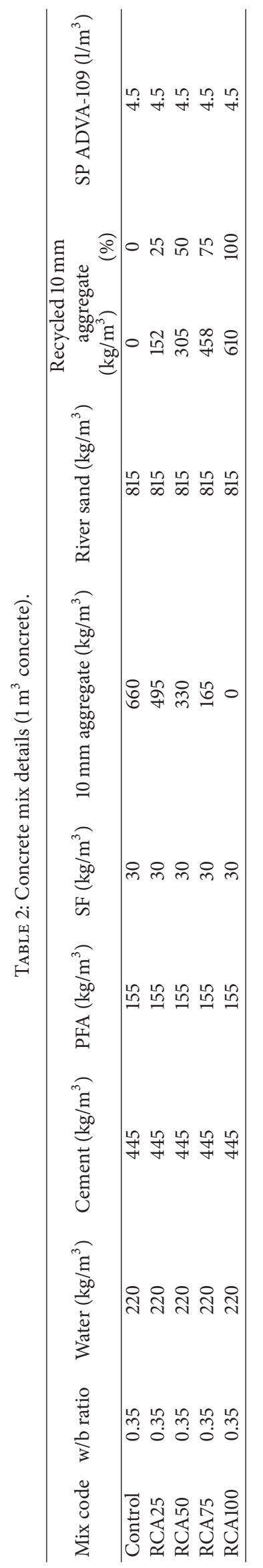




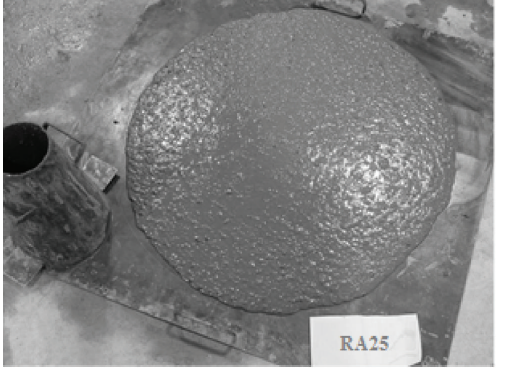

(a)

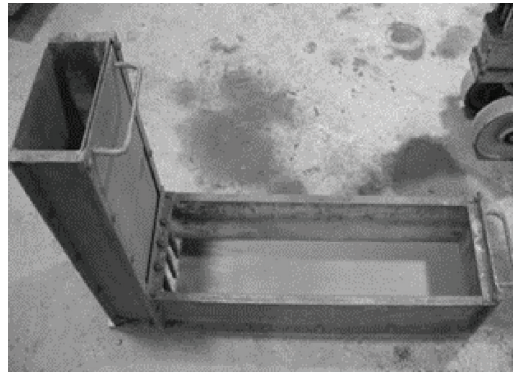

(b)

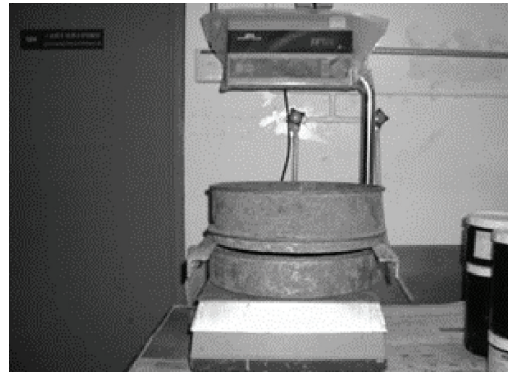

(c)

FIGURE 1: (a) Slump flow tests, (b) L-box test, and (c) sieve segregation test.

The slump flow test and L-box test were carried out at two different times for each of the SCC mixes. The first set of tests were performed directly after mixing, while the second set of tests were carried out 1 hour after mixing to evaluate any changes in the workability of the SCC over time. During the 1-hour rest period, the concrete mixture was not agitated, but the mixture was remixed for about 1 min using the initial mixing speed before the second measurements were performed.

2.2.2. Hardened Concrete Tests. Standard concrete specimens were cast to study the strength properties (compressive strength, $f_{c}$, tensile strength, $f_{t}$, and elastic modulus, $E$ ) according to the relevant British and European standards [29-31]. Notched concrete beams with the dimensions $75 \times$ $75 \times 250 \mathrm{~mm}$ were used to study the fracture properties according to RILEM recommendations [32]. The bending tests were conducted using a servo-controlled MTS universal testing machine. Before testing the beam samples, a notch $20 \mathrm{~mm}$ in depth and $2 \mathrm{~mm}$ in thickness was saw-cut at the midsection of each beam. The test setup, including details of the notched beam, is shown in Figure 2. During the test, the crack mouth opening displacement (CMOD) was measured using a clip gauge clipped to the bottom of the beam and held in position by two steel knife edges glued to the specimen. The displacement rate was controlled at a suitable rate until the specimens failed.

The determination of the fracture energy $\left(G_{f}\right)$ was based on load-deflection measurements in accordance with the RILEM standard [32] as given by

$$
G_{f}=\frac{W_{0}+m \cdot g \cdot \delta_{0}}{b \cdot\left(d-a_{0}\right)}
$$

where $W_{0}$ is the area under the load-deflection curve, $\delta_{0}$ is the deflection when the load is zero, $g$ is the gravity factor, $m$ is mass of beam, $b$ is width of beam, $d$ is depth of beam, and $a_{0}$ is the notch depth of the beam. In order to acquire stable crack propagation in the beam during the postpeak response, the use of load-crack mouth opening displacements (load-CMOD) for evaluation of the fracture energy of concrete was suggested [33,34]. To account for the difference in the fracture energy between load-deflection and load-CMOD variations, a correction factor was adopted by Navalurkar et al. (1999) [34]. This approach was used herein

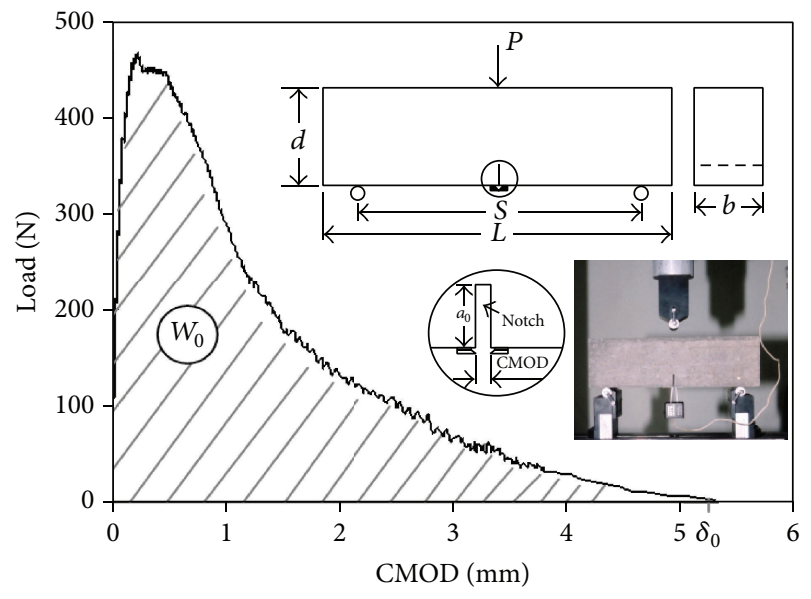

Figure 2: Typical experimental load-CMOD plot with testing configuration (span length $=200 \mathrm{~mm}$ ).

with a correction factor of 0.800 as appropriate for a notch depth ratio, $a_{0} / d=0.25$, and span-to-depth ratio $=2.7$.

The characteristic length $\left(l_{\mathrm{ch}}\right)$ proposed by Hillerborg [35] in the fictitious crack model is often used to characterise the brittleness of concrete and is given by

$$
l_{\mathrm{ch}}=\frac{G_{f} \cdot E}{f_{t}^{2}} .
$$

As stated by Zhou et al. [36], the smaller the value of $l_{\mathrm{ch}}$, the more brittle the material. It has also been found, however, that the value of characteristic length is reduced as the compressive strength increases, leading to the development of a modified form of the characteristic length $\left(l_{\mathrm{ch}, \bmod }\right)$ as follows [33]:

$$
l_{\mathrm{ch}, \bmod }=\frac{G_{f} \cdot E}{f_{t} \cdot f_{c}} .
$$

The characteristic length is calculated herein in accordance with the work of Rao and Prasad [33] using (3). It is noted that the Hillerborg method (also known as the workof-fracture method) presented in (1) to (3) has a number of limitations. The most notable of these is the size dependency of the method, with previous researchers finding that fracture 


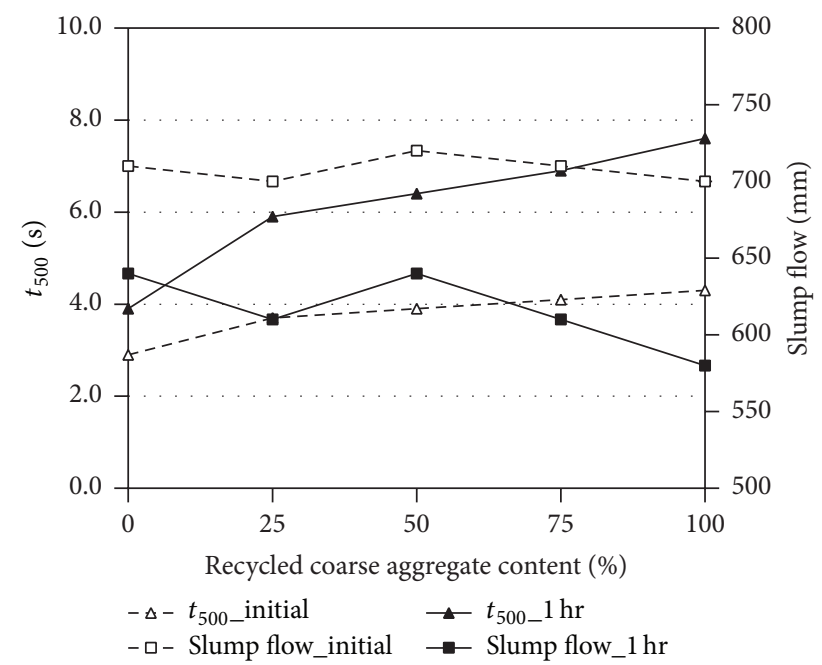

Figure 3: Effect of RCA content on slump flow and $t_{500}$ times for SCC.

energy increases with test beam size $[17,18]$. However, as outlined in Section 1 the purpose of the study herein is to investigate the relative performance of a control SCC and SCCs with RCA utilised at various natural coarse aggregate replacement levels. Thus the absolute values of $G_{f}$ or $l_{\mathrm{ch} \text {,mod }}$ are not of primary concern but rather the relative values obtained for the different SCCs. Thus, a single beam size was used for all test specimens herein, and the fracture energy results are presented in Section 3 of this paper in terms of the performance of the RCA SCCs relative to the control SCC (0\% RCA).

\section{Results and Discussion}

\subsection{Fresh Concrete Properties}

3.1.1. Water Absorption of RCA. As can be seen in Table 1, the increased porosity of RCA, when compared to natural aggregates, results in a greater water absorption capacity in the RCA. This enhances the potential for water interchange with the surrounding paste in the RCA concretes, meaning RCA particles can have a greater role in absorbing water from or providing water to the SCC mortar. As stated by Casuccio et al. [6] this is an unwanted source of variation when comparing RCA concretes and concretes containing only natural aggregates, as RCA used in the dry condition may absorb some water from the mortar phase, and RCA used in the saturated phase may slightly increase water content.

3.1.2. Fresh Concrete Test Results. The test results of slump flow, blocking ratio, and sieve segregation for the control SCC and the SCCs with various levels of RCA utilisation are presented in Table 3 and illustrated in Figures 3-5, respectively. Firstly, considering the slump flow test results, displayed graphically, it is noted from Figure 3 that the initial measurements indicated that the addition of RCA up to $100 \%$ did not impact upon slump flow diameter; however, the $t_{500}$ times increased with increasing RCA content. This result

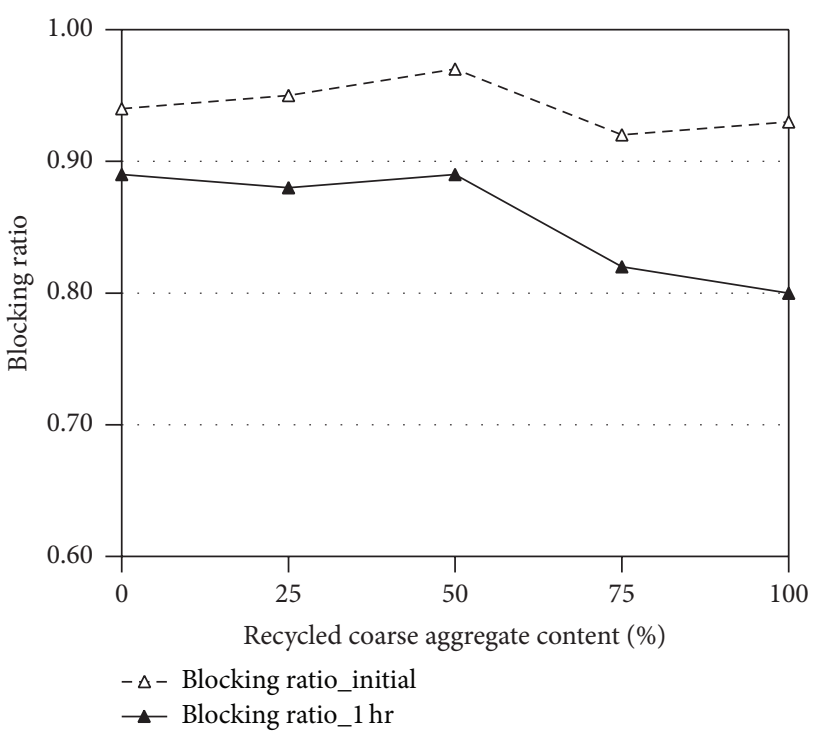

FIGURE 4: Effect of RCA content on blocking ratio of SCC mixes.

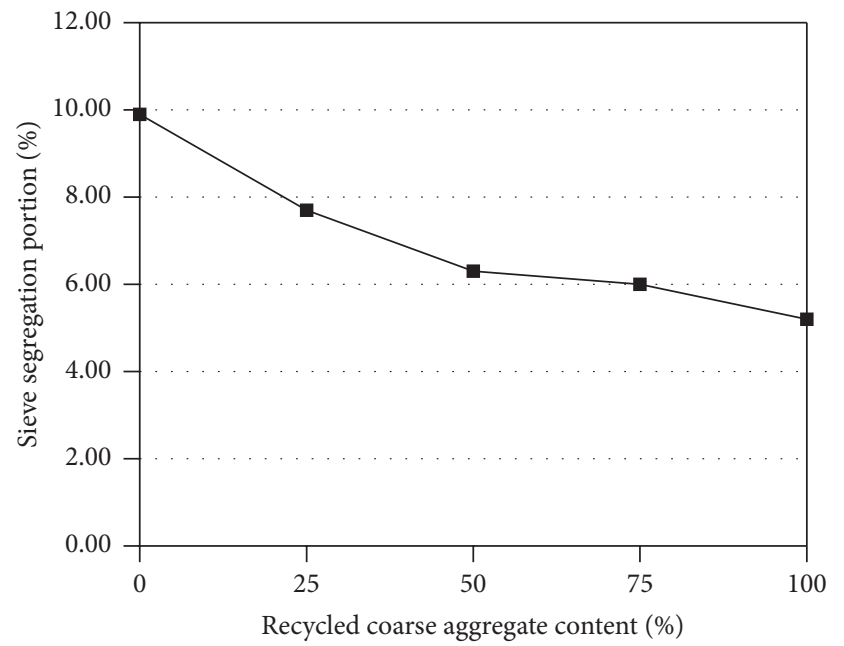

FIgURE 5: Effect of RCA content on sieve segregation resistance for SCC mixes.

indicates similar flowability across all SCCs but increased viscosity with increasing RCA content. A similar pattern was observed in the slump flow tests conducted one hour after concrete mixing; however the $t_{500}$ times experienced a greater percentage increase with increasing RCA content; that is, from control to $100 \%$ RCA $t_{500}$ increases by $48 \%$ at initial measurement and $94 \%$ after 1 hour (see Table 3 ). The onehour slump flow diameter for the $100 \%$ RCA is also notably smaller than the control SCC. The increase in viscosity with increasing RCA content may be due to the angular shape of the RCA, while it is possible that the time dependent change in the slump flow results was caused by continued water absorption of the recycled aggregate, despite having been presoaked and dried for one hour before use. As seen in Table 1 the RCA had approximately seven times more absorption capacity than the natural aggregates, meaning 


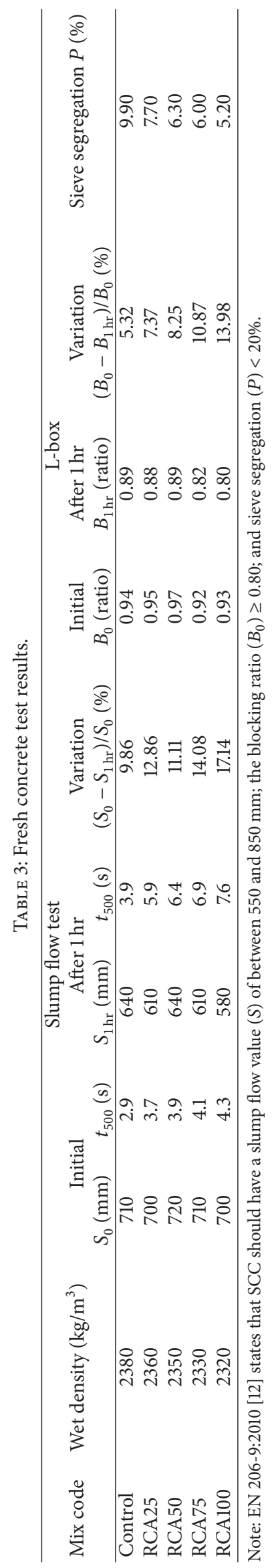


TABLE 4: Strength properties of control and RCAs.

\begin{tabular}{lccc}
\hline Mix code & $\begin{array}{c}\text { Compressive } \\
\text { strength, } \\
f_{c}(\mathrm{MPa})\end{array}$ & $\begin{array}{c}\text { Tensile strength, } \\
f_{t}(\mathrm{MPa})\end{array}$ & $\begin{array}{c}\text { Young's } \\
\text { modulus, } \\
E(\mathrm{GPa})\end{array}$ \\
\hline Control & 59.4 & 4.1 & 31.5 \\
RCA25 & 63.7 & 4.9 & 30.3 \\
RCA50 & 65.3 & 4.1 & 29.5 \\
RCA75 & 60.0 & 3.9 & 28.5 \\
RCA100 & 53.8 & 3.8 & 24.5 \\
\hline
\end{tabular}

even though both aggregate types were soaked for 24 hours and subsequently dried for 1 hour, the RCAs are likely to have had a greater capacity to absorb free water after this process.

The results of the L-box test are presented in Figure 4. As stated in the previous section this test measures the passing ability of the SCC, thus quantifying the suitability of the SCC for use in a member with congested reinforcement. From the figure it is clear that the replacement of natural coarse aggregates with coarse RCA has little impact on the initial blocking ratios, with only a very slight reduction in $B_{0}$ observed for the $75 \%$ and $100 \%$ RCA utilisation levels. However, for the L-box test carried out one hour after mixing, the difference between the control SCC and the SCCs containing 75\% RCA and 100\% RCA increases. For this test the reductions in the blocking ratio observed, when compared to the control SCC, are approximately $8 \%$ and $10 \%$ for the $75 \%$ and $100 \%$ RCA SCCs, respectively (see Table 3 ). This results in the SCC containing 100\% RCA being only just inside the EN206-9:2010 [12], SCC passing ability tolerance of 0.80 . As with the slump flow test results, this time dependent change in blocking ratio at the higher levels of RCA utilisation may have been caused by continued absorption of free water by the RCA after concrete mixing. Examining Figure 5, it can be seen that the segregation resistance of the SCCs increased with increasing RCA content. Again this is likely to be due to the higher water absorption capacity of the recycled concrete aggregates. All the SCCs were deemed appropriate in accordance with EN206-9:2010 [12], with each SCC mix falling into the sieve segregation resistance class SR2 (segregation portion $\leq 15 \%$ ).

3.2. Strength Properties. The test results for concrete compressive strength, splitting tensile strength, and the static modulus of elasticity are presented in Table 4. Figure 6 facilitates the easy comparison of the control mix results and the RCA mixes results, by presenting the RCA SCC strength properties relative to the control SCC properties. Taking the RCA25 mix as an example, the compressive strength value of RCA25 was 7\% greater than the compressive strength of the control mix, that is, relative compressive strength performance of $107 \%$. Thus the RCA25 compressive strength bar in Figure 6 lies above the $100 \%$ line, representing a higher compressive strength than the control SCC.

Considering the compressive strength results from Figure 6 it is noted that the replacement of conventional aggregates with recycled concrete at percentages of $25 \%$

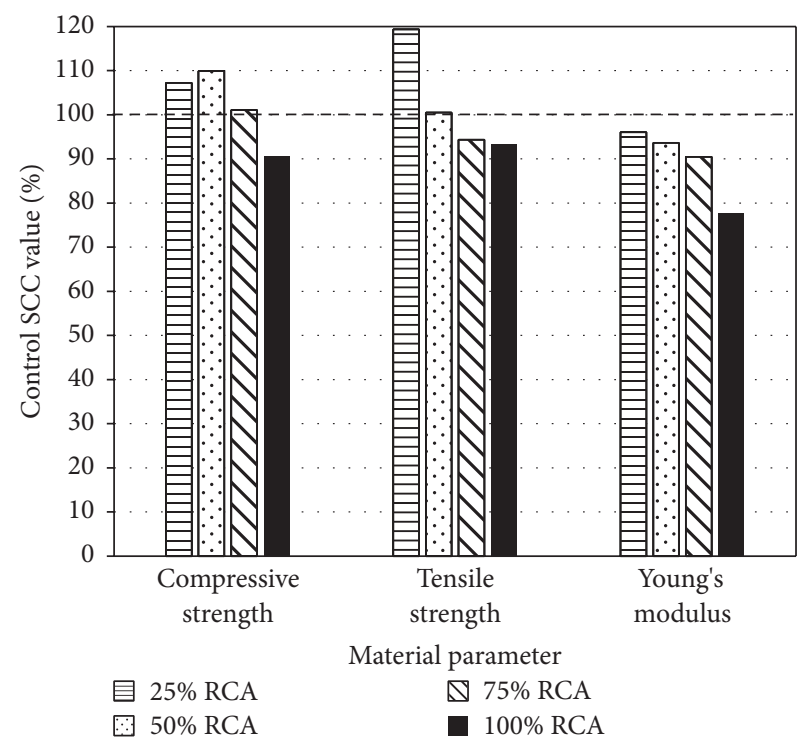

FIGURE 6: Relative comparison of RCA and control concrete strength properties.

and $50 \%$ actually increased the compressive strength by $7 \%$ and $10 \%$, respectively. At the $75 \%$ replacement rate the compressive strength was found to be almost exactly equal to the control concrete, while $100 \%$ replacement with recycled aggregate resulted in a drop in compressive strength of $10 \%$. Tuyan et al. [3] obtained similar findings when comparing SCC concretes containing 20\%, 40\%, and 60\% RCA for a concrete with a w/b ratio of 0.43 . These authors found the change in compressive strength to be $+5 \%,+9 \%$, and $-2 \%$ for $20 \%, 40 \%$, and $60 \%$ replacement, respectively. In an examination of high performance vibrated concretes Andreu and Miren [37] identified similar trends, although the changes for the vibrated concretes examined in the Andreu and Miren study were generally smaller.

There are a number of possible reasons for the increase in compressive strength with addition of RCA up to $50 \%$. Hoffmann et al. [38] and Tuyan et al. [3] have both highlighted the fact that the increased surface roughness of recycled aggregates can increase cement aggregate bond. The role of the differing water absorption coefficients in recycled aggregates and conventional aggregates is also likely to have some influence. As shown herein and in other published studies, RCAs have a higher water absorption capacity than natural aggregates [4]. This increased water absorption may reduce the $\mathrm{w} / \mathrm{c}$ ratio in the ITZ, increasing the strength of the cement paste in improving the bond between aggregates and cement paste $[37,39]$. However, as pointed out by Tu et al. [4], if too much water is absorbed insufficient water content and poor hydration will reduce strength development in the concrete. This optimal water content balance is a possible explanation for the increase in compressive strength up to $50 \%$ RCA level, followed by the decrease in compressive strength from $50 \%$ RCA to $100 \%$ RCA, where w/b ratio remains constant at 0.35 , regardless of RCA content. It is however also noted that the decrease in compressive strength 
TABLE 5: Fracture properties test results.

\begin{tabular}{|c|c|c|c|c|c|c|c|}
\hline \multirow{2}{*}{ Mix code } & \multirow{2}{*}{$f_{c}\left(\mathrm{~N} / \mathrm{mm}^{2}\right)$} & \multirow{2}{*}{$f_{t}\left(\mathrm{~N} / \mathrm{mm}^{2}\right)$} & \multirow{2}{*}{$E\left(\mathrm{kN} / \mathrm{mm}^{2}\right)$} & \multicolumn{2}{|c|}{$G_{f}$} & \multicolumn{2}{|c|}{$l_{\mathrm{ch}, \bmod }$} \\
\hline & & & & $(\mathrm{Nm}-1)$ & $(\%)$ & $(\mathrm{mm})$ & $(\%)$ \\
\hline Control & 59.4 & 4.08 & 31.5 & 170.8 & 100.0 & 22.2 & 100 \\
\hline RCA25 & 63.7 & 4.87 & 30.3 & 165.1 & 96.7 & 16.1 & 72.6 \\
\hline RCA50 & 65.3 & 4.1 & 29.5 & 164.6 & 96.4 & 18.1 & 81.8 \\
\hline RCA75 & 60.0 & 3.85 & 28.5 & 125.4 & 73.4 & 15.5 & 69.7 \\
\hline RCA100 & 53.8 & 3.81 & 24.5 & 126.2 & 73.9 & 15.1 & 68 \\
\hline
\end{tabular}

Notes: $f_{c}=$ compressive strength; $f_{t}=$ splitting tensile strength; $E=$ modulus of elasticity; $G_{f}=$ fracture energy; $l_{\text {ch,mod }}=$ modified characteristic length.

even at $100 \%$ replacement with RCA was found to be less than $10 \%$, indicating the suitability of RCA utilisation. Authors examining conventional vibrated concretes have identified greater reductions in compressive strength when 100\% RCA is used at replacement level; however as pointed out by Tuyan et al. [3], SCCs are likely to experience a reduced effect of addition of RCA due to the reduced content of coarse aggregates in SCC mixes (which typically have an aggregate content comprising more than $50 \%$ fines).

The tensile strength results in Figure 6 exhibit a somewhat similar pattern to the compressive strength results, with the tensile strength initially increasing at the lower levels of RCA utilisation, followed by a decrease in strength beyond $50 \%$ RCA content. The tensile strength for the 25\% RCA replacement is almost $20 \%$ greater than the control SCC. More subtle changes in tensile strength occur when the RCA content is greater than 25\%. In similar tests Grdic et al. [15] found that the tensile strength for SCCs with 50\% RCA and $100 \%$ RCA coarse aggregates resulted in approximate reductions in tensile strength of $2.5 \%$ and $14 \%$, respectively, when compared to a control mix. Tuyan et al. [3] found that the splitting tensile strength reduced for $20 \%, 40 \%$, and $60 \%$ RCA by $8.8 \%, 11.1 \%$, and $16 \%$, respectively, owing to the higher porosity and lower specific gravity of the RCA when compared to the natural aggregates. It should be noted however that, in contrast to the tests carried out herein, both Grdic et al. [15] and Tuyan et al. [3] increased water content in mix designs with increasing RCA content. Andreu and Miren [37] did not increase water content with increasing RCA content in their study of vibrated concretes containing RCA. These authors found that the use of $20 \%$ RCA increased the splitting tensile strength by between approximately $3 \%$ and $22 \%$, a finding consistent with the results obtained herein.

Finally in terms of Figure 6, it is clear that the use of RCA at any replacement level resulted in a reduction in modulus of elasticity. The reduction in modulus of elasticity increases with increasing RCA content to a maximum of $22.2 \%$ for the $100 \%$ RCA concrete. The reduction for the $75 \%$ RCA mix is also substantial at $9.5 \%$. As pointed out by Andreu and Miren [37], who obtained similar results for vibrated concretes containing RCA, such reductions are to be expected given that the modulus of elasticity of concrete is related to the modulus of elasticity of the coarse aggregate [40], with studies indicating that the modulus of elasticity is proportional to the square root of the aggregate density [41].

Overall considering the three strength property tests, the experimental programme indicated that the use of RCA in

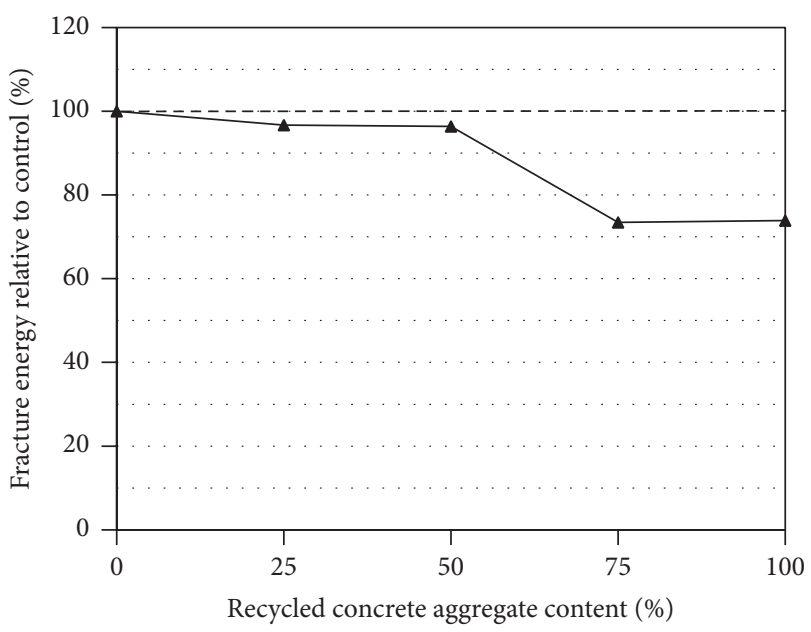

FIGURE 7: Influence of RCA coarse aggregate content on fracture energy.

proportions of $25 \%$ to $50 \%$ does not negatively impact upon the compressive and tensile strength of SCC. In fact, even up to the $100 \%$ RCA utilisation level, reductions in these parameters were less than $10 \%$ when compared to the control SCC. However, reductions in Young's modulus increased with increasing RCA utilisation across all SCCs, with the modulus of elasticity for the $100 \%$ RCA SCC $22 \%$ less than the control SCC, highlighting an issue relating to the brittleness of SCCs constructed entirely with RCA.

3.3. Fracture Properties. The fracture properties for the control concrete and the concrete mixes containing RCAs are presented in Table 5. As in the previous section, graphical presentation of the results is in the form of relative performance, with the fracture properties of the mixes containing RCA plotted, relative to the values for the control SCC. This facilitates easy visual comparison of the performance of RCA SCC mixes and the control SCC mix. Figure 7 presents the change in fracture energy with increasing RCA content.

As can be seen from the plot the fracture energy in the concrete was found to be relatively unaffected by the utilisation of $25 \%$ and 50\% RCA, with these mixes having $96.7 \%$ and $96.4 \%$ of the control concrete $G_{f}$ value, respectively. However, a sudden reduction in fracture energy occurs at the $75 \%$ RCA utilisation level, with $75 \%$ RCA mix and the $100 \%$ RCA mix both resulting in a $26 \%$ reduction in fracture energy. As discussed in Section 1, there is little or no existing 


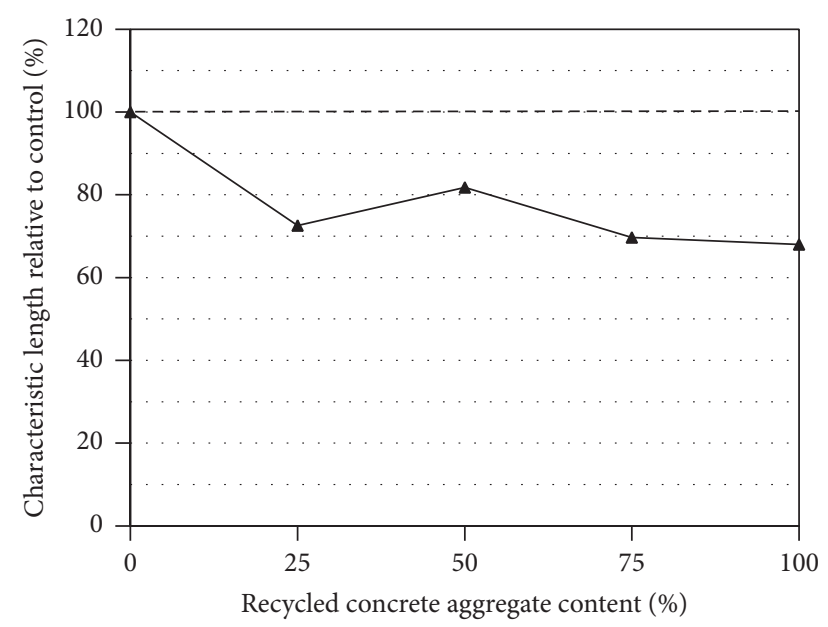

FIGURE 8: Influence of RCA coarse aggregate content on characteristic length.

literature examining fracture energy of SCC with RCAs. There are however a limited number of studies which explore fracture energy of traditional vibrated concretes containing RCA, while a number of these studies consider only $0 \%$ RCA (control) or 100\% RCA [6, 20]. Bordelon et al. [19] examined a control concrete, a 50\% RCA concrete, and a $100 \%$ concrete. In a similar pattern to the results obtained herein, Bordelon et al. found that, at the $50 \%$ replacement level, fracture energy was $98.8 \%$ of the control concrete; however for the $100 \%$ RCA vibrated concrete the fracture energy reduced by $35 \%$. It is possible that the pattern of maintained fracture energy up to $50 \%$ RCA followed by stark reduction at RCA levels greater than $50 \%$ could be due to a balance of aggregate strength and aggregate bond. As discussed in the previous section aggregate-cement paste bond can be increased due to utilisation of RCA [3, 38]; however as pointed out by Butler et al. [20] and Darwin et al. [42], it is generally found that as aggregate strength decreases, fracture energy decreases. Thus, if a large portion of the total coarse aggregate volume comprises the weaker RCA (in comparison with natural granite aggregate) one might expect the fracture energy to reduce substantially. The fact that this does not occur until beyond the 50\% RCA utilisation level in SCC examined herein is, however, an interesting experimental finding.

Figure 8 presents the change in characteristic length, $l_{\mathrm{ch} \text {,mod }}$, with increasing RCA content. As stated in Section 2, $l_{\mathrm{ch} \text {,mod }}$ parameter is a measure of brittleness derived from fracture energy, modulus of elasticity, compressive strength, and tensile strength. As can be seen from the plot the utilisation of RCA at all levels results in a notable reduction in characteristic length (increased brittleness), with relative $l_{\text {ch,mod }}$ values of $81.8 \%$ to $68.0 \%$ obtained for the RCA concretes. This is primarily due to the decrease in modulus of elasticity experienced in concretes containing RCA (discussed previously in the context of Figure 6). The low relative $l_{\text {ch,mod }}$ value for the $25 \%$ RCA mix is due to the nature of (3) and the 25\% RCA mix having higher $f_{c}$ and $f_{t}$ values than the control concrete, as discussed in the previous section. Again, due to a lack of existing research in this area it is not possible to compare these findings to other studies examining SCC containing RCAs; however, Casuccio et al. [6] did obtain characteristic length values for a range of vibrated concretes containing RCAs. These authors found that when compared to a control concrete, incorporation of $100 \%$ RCA across three concrete strength groups resulted in reductions in characteristic length of between $0 \%$ and $36 \%$ with an average reduction of $17 \%$. This is in reasonable agreement with the study of SCCs and RCA herein which indicated that the use of RCAs brings about a notably more brittle concrete, with changes of $19 \%$ to $32 \%$ in characteristic length observed.

\section{Conclusions}

The work presented in this paper builds on the existing SCC literature by investigating the effect of incorporating various levels of RCA on workability, strength characteristics, and most importantly fracture properties. The workability tests revealed that the viscosity of the SCCs increased with increasing RCA content, as did sieve segregation resistance. The passing ability of the SCC was found to notably reduce for RCA utilisation greater than 50\%; however, the 75\% RCA and $100 \%$ RCA SCCs were still within allowable passing ability limits.

Experimental investigation into the strength characteristics of the SCCs, namely, $f_{c}, f_{t}$, and $E$, indicated that the use of coarse RCA in proportions of $25 \%$ to $75 \%$ did not notably impact upon the strength of SCC. However, the modulus of elasticity for the $100 \%$ RCA SCC was found to be notably reduced when compared to the control SCC, highlighting a possible issue with brittleness of SCCs constructed entirely with RCA.

The fracture energy was found to remain relatively constant from control SCC to $25 \%$ RCA SCC to 50\% RCA. However, a significant reduction in fracture energy was observed for the 75\% RCA and 100\% RCA utilisation levels. This sudden reduction in the fracture energy beyond the $50 \%$ RCA utilisation is an interesting finding in the context of the lack of information in the literature in this area. Overall the experimental test results obtained herein indicate that the environmental and economic aspects of SCC could be improved, without impact upon workability, strength characteristics, or fracture properties, through utilisation of 25 to $50 \%$ RCA. However, even at this lower level of replacement, some increase in concrete brittleness is likely to occur.

\section{Conflict of Interests}

The authors declare that there is no conflict of interests regarding the publication of this paper.

\section{Acknowledgments}

The work described in this paper was supported by the Australian Research Council Discovery Project (no. G1500225) and Faculty Strategic Pilot Grant and the Centre for 
Interdisciplinary Built Environment Research, the University of Newcastle, Australia.

\section{References}

[1] A. K. Padmini, K. Ramamurthy, and M. S. Mathews, "Influence of parent concrete on the properties of recycled aggregate concrete," Construction and Building Materials, vol. 23, no. 2, pp. 829-836, 2009

[2] M. D. Safiuddin, U. J. Alengaram, M. A. Salam, M. Z. Jumaat, F. F. Jaafar, and H. B. Saad, "Properties of high-workability concrete with recycled concrete aggregate," Materials Research, vol. 14, no. 2, pp. 248-255, 2011.

[3] M. Tuyan, A. Mardani-Aghabaglou, and K. Ramyar, "Freezethaw resistance, mechanical and transport properties of selfconsolidating concrete incorporating coarse recycled concrete aggregate," Materials and Design, vol. 53, pp. 983-991, 2014.

[4] T.-Y. Tu, Y.-Y. Chen, and C.-L. Hwang, "Properties of HPC with recycled aggregates," Cement and Concrete Research, vol. 36, no. 5, pp. 943-950, 2006.

[5] S. C. Kou and C. S. Poon, "Properties of self-compacting concrete prepared with recycled glass aggregate," Cement and Concrete Composites, vol. 31, no. 2, pp. 107-113, 2009.

[6] M. Casuccio, M. C. Torrijos, G. Giaccio, and R. Zerbino, "Failure mechanism of recycled aggregate concrete," Construction and Building Materials, vol. 22, no. 7, pp. 1500-1506, 2008.

[7] J. Xiao, J. Li, and C. Zhang, "Mechanical properties of recycled aggregate concrete under uniaxial loading," Cement and Concrete Research, vol. 35, no. 6, pp. 1187-1194, 2005.

[8] RILEM Recommendation 121-DRG Guidance for Demolition and Reuse of Concrete and Masonry, "Specifications for concrete with recycled aggregates," Materials and Structures, vol. 27, no. 9, pp. 557-559, 1994.

[9] ACI Committee 555, "Removal and reuse of hardened concrete," ACI Materials Journal, vol. 99, no. 3, pp. 300-325, 2002.

[10] A. Katz, "Properties of concrete made with recycled aggregate from partially hydrated old concrete," Cement and Concrete Research, vol. 33, no. 5, pp. 703-711, 2003.

[11] P. C. Ryan and A. O'Connor, "Examination of self-compacting concrete options for marine bridge applications," Journal of Bridge Engineering, vol. 19, no. 9, Article ID 04014032, 2014.

[12] Centre Europeen de Normalisation (CEN), EN 206-9: 2010 Additional Rules for Self Compacting Concrete, 2010.

[13] W. Zhu and P. J. M. Bartos, "Permeation properties of selfcompacting concrete," Cement and Concrete Research, vol. 33, no. 6, pp. 921-926, 2003.

[14] P. C. Ryan and A. J. O'Connor, "Probabilistic modeling of reinforced concrete bridge repair deterioration in marine environments," in Proceedings of the 6th International Conference on Bridge Maintenance, Safety and Management (IABMAS '12), pp. 3776-3783, Taylor \& Francis Publishers, Stresa, Italy, July 2012.

[15] Z. J. Grdic, G. A. Toplicic-Curcic, I. M. Despotovic, and N. S. Ristic, "Properties of self-compacting concrete prepared with coarse recycled concrete aggregate," Construction and Building Materials, vol. 24, no. 7, pp. 1129-1133, 2010.

[16] C. G. Fakitsas, P. E. A. Papakonstantinou, P. D. Kiousis, and A. Savva, "Effects of recycled concrete aggregates on the compressive and shear strength of high-strength self-consolidating concrete," Journal of Materials in Civil Engineering, vol. 24, no. 4, pp. 356-361, 2012.
[17] M. H. A. Beygi, M. T. Kazemi, I. M. Nikbin, and J. V. Amiri, "The effect of water to cement ratio on fracture parameters and brittleness of self-compacting concrete," Materials \& Design, vol. 50, pp. 267-276, 2013.

[18] Z. P. Bažant and J. Planas, Fracture and Size Effect in Concrete and Other Quasibrittle Materials, CRC Press, Boca Raton, Fla, USA, 1998.

[19] A. Bordelon, V. Cervantes, and J. R. Roesler, "Fracture properties of concrete containing recycled concrete aggregates," Magazine of Concrete Research, vol. 61, no. 9, pp. 665-670, 2009.

[20] L. Butler, J. S. West, and S. L. Tighe, "Effect of recycled concrete coarse aggregate from multiple sources on the hardened properties of concrete with equivalent compressive strength," Construction and Building Materials, vol. 47, pp. 1292-1301, 2013.

[21] A. Leemann, R. Loser, and B. Münch, "Influence of cement type on ITZ porosity and chloride resistance of self-compacting concrete," Cement and Concrete Composites, vol. 32, no. 2, pp. 116-120, 2010.

[22] M. Valcuende and C. Parra, "Bond behaviour of reinforcement in self-compacting concretes," Construction and Building Materials, vol. 23, no. 1, pp. 162-170, 2009.

[23] Centre Europeen de Normalisation (CEN), EN 4501:2005+A1:2007 Fly Ash for Concrete. Definition, Specifications and Conformity Criteria, 2007.

[24] ASTM, "Standard specification for silica fume used in cementitious mixtures," ASTM C1240-11, ASTM International, West Conshohocken, Pa, USA, 2011.

[25] Centre Europeen de Normalisation (CEN), BS EN 12620:2002+ A1:2008 Aggregates for Concrete, 2002.

[26] Centre Europeen de Normalisation (CEN), EN 12350-8: 2010,Testing Fresh Concrete Part 8: Self-Compacting ConcreteSlumpflow Test, 2010.

[27] Centre Europeen de Normalisation (CEN), EN 12350-10: 2010, Testing Fresh Concrete Part 10: Self-Compacting ConcreteL-Box Test, 2010.

[28] Centre Europeen de Normalisation CEN, "Self compacting concrete-sieve segragation test," EN 12350-11:2010, 2010.

[29] Centre Europeen de Normalisation (CEN), EN 12390-3:2009 Testing Hardened Concrete. Compressive Strength of Test Specimens, 2009.

[30] Centre Europeen de Normalisation CEN, “Testing hardened concrete. Tensile splitting strength of test specimens," EN 123906:2000, 2000.

[31] British Standards Institution, "Testing concrete. Method for determination of static modulus of elasticity in compression," BS 1881-121:1983, HMSO, London, UK, 1981.

[32] RILEM, "Determination of the fracture energy of mortar and concrete by means of three-point bend tests on notched beams," Materials and Structures, vol. 18, no. 4, pp. 285-290, 1985.

[33] G. A. Rao and B. K. R. Prasad, "Fracture energy and softening behavior of high-strength concrete," Cement and Concrete Research, vol. 32, no. 2, pp. 247-252, 2002.

[34] R. K. Navalurkar, C.-T. T. Hsu, S. K. Kim, and M. Wecharatana, "True fracture energy of concrete," ACI Materials Journal, vol. 96, no. 2, pp. 213-225, 1999.

[35] A. Hillerborg, "Analysis of one single crack," in Fracture Mechanics of Concrete, Developments in Civil Engineering, pp. 223-249, Lund University Publications, Lund, Sweden, 1983.

[36] F. P. Zhou, B. I. G. Barr, and F. D. Lydon, "Fracture properties of high strength concrete with varying silica fume content and 
aggregates," Cement and Concrete Research, vol. 25, no. 3, pp. 543-552, 1995.

[37] G. Andreu and E. Miren, "Experimental analysis of properties of high performance recycled aggregate concrete," Construction and Building Materials, vol. 52, pp. 227-235, 2014.

[38] C. Hoffmann, S. Schubert, A. Leemann, and M. Motavalli, "Recycled concrete and mixed rubble as aggregates: influence of variations in composition on the concrete properties and their use as structural material," Construction and Building Materials, vol. 35, pp. 701-709, 2012.

[39] M. Etxeberria, E. Vázquez, and A. Marí, "Microstructure analysis of hardened recycled aggregate concrete," Magazine of Concrete Research, vol. 58, no. 10, pp. 683-690, 2006.

[40] A. M. Neville, Properties of Concrete, Longman, Harlow, UK, 4th edition, 1995.

[41] F. D. Lydon and R. V. Balendran, "Some observations on elastic properties of plain concrete," Cement and Concrete Research, vol. 16, no. 3, pp. 314-324, 1986.

[42] D. Darwin, S. Barham, R. Kozul, and S. Luan, "Fracture energy of high-strength concrete," ACI Materials Journal, vol. 98, no. 5, pp. 410-417, 2001. 

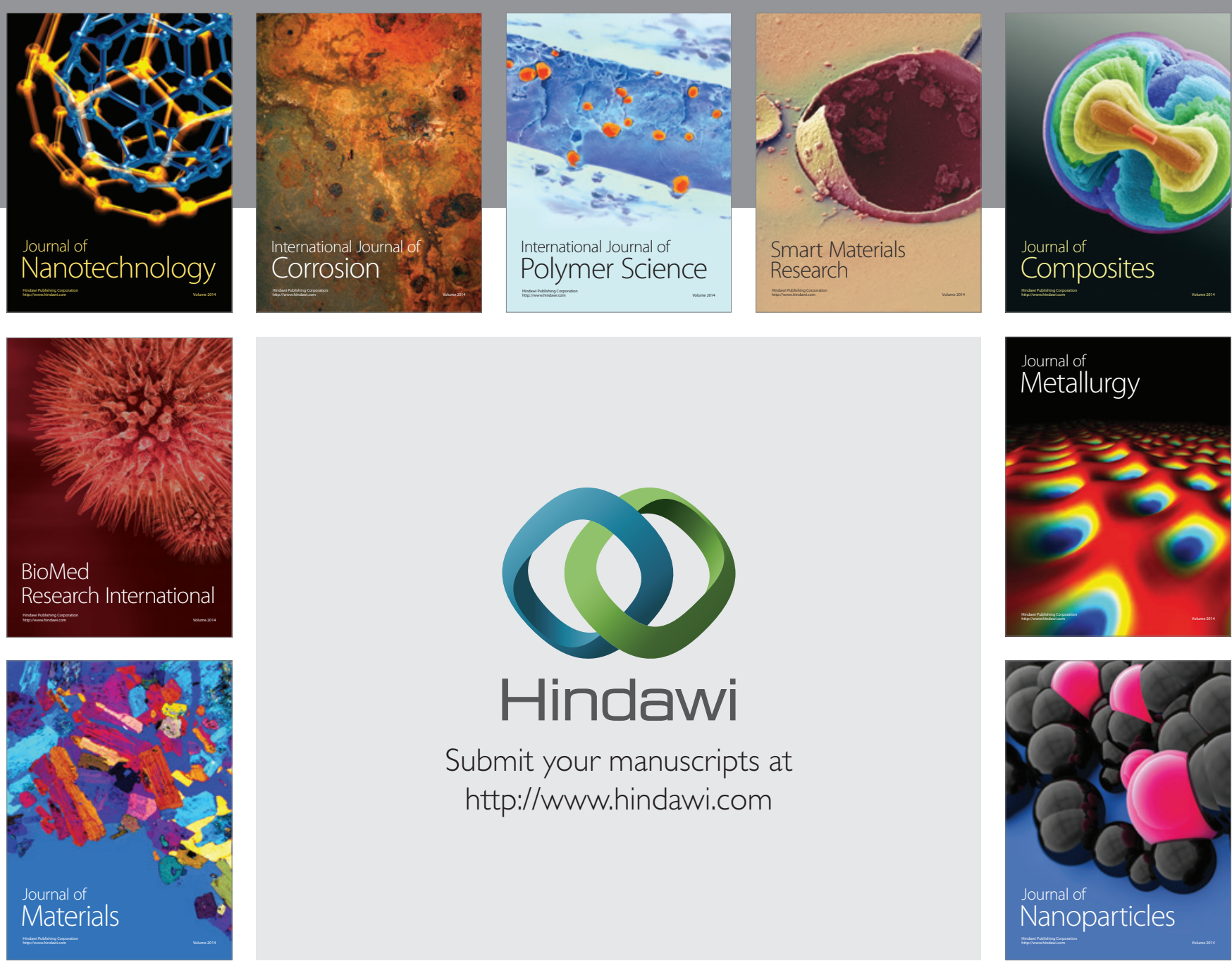

\section{Hindawi}

Submit your manuscripts at

http://www.hindawi.com

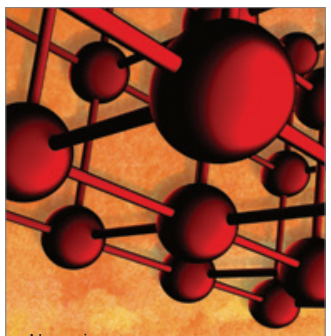

Materials Science and Engineering
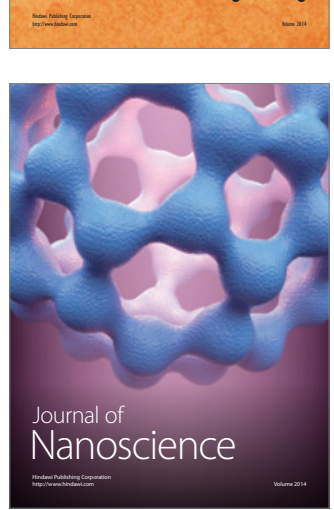
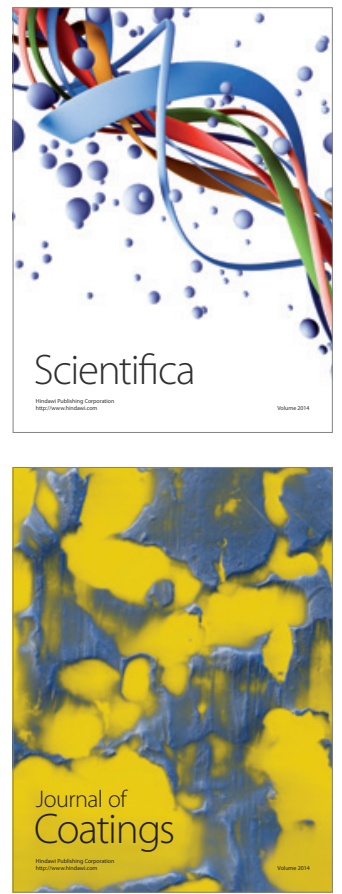
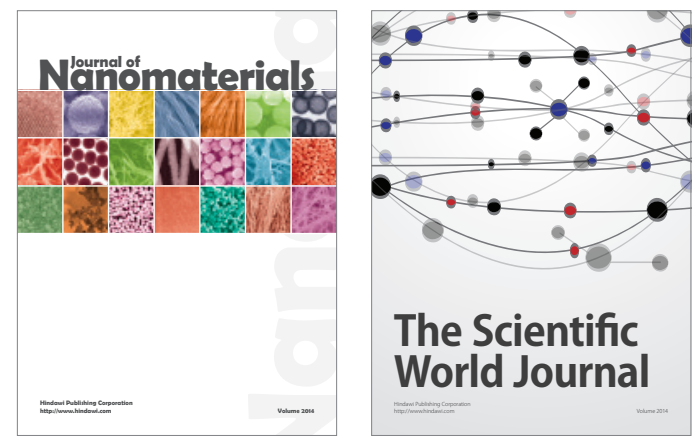

The Scientific World Journal
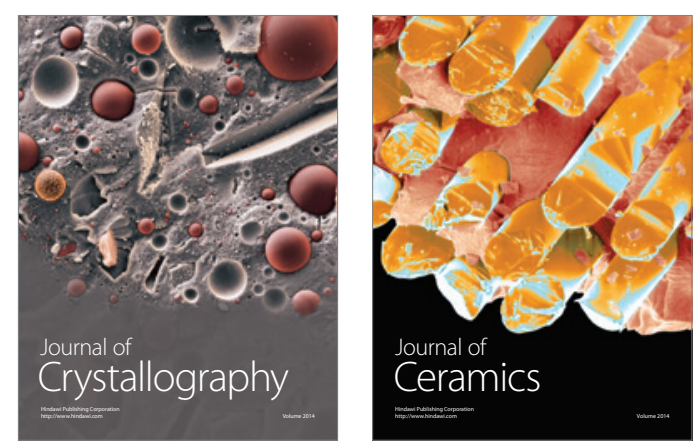
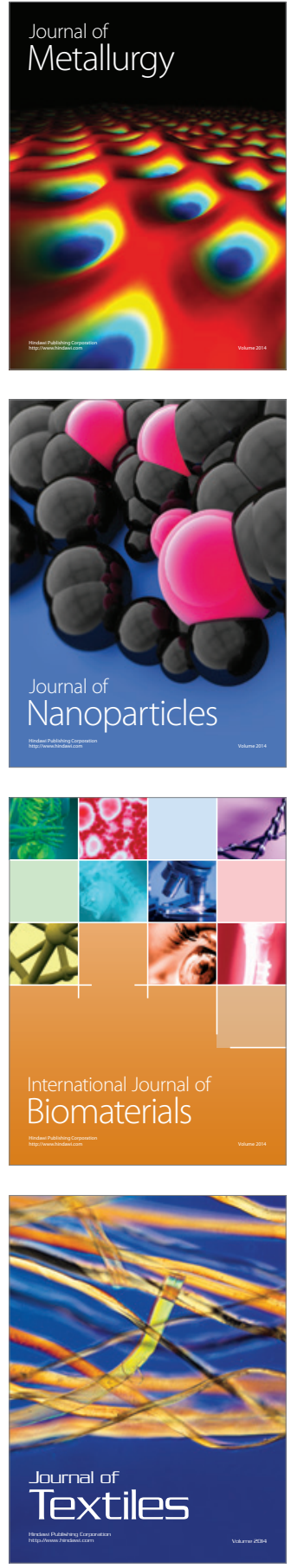